\title{
Using management scenarios and a participatory approach to encourage model adoption in managing invasive species
}

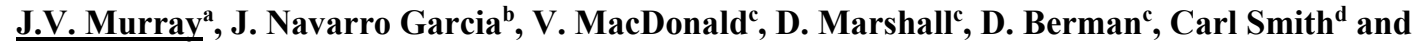 \\ R.D. van Klinken ${ }^{\mathrm{a}}$ \\ ${ }^{a}$ CSIRO Health and Biosecurity Flagship, GPO Box 2583 Brisbane Qld, Australia. 4001 \\ ${ }^{b}$ CSIRO Land and Water Flagship, GPO Box 2583 Brisbane Qld, Australia. 4001 \\ ${ }^{c}$ Queensland Murray Darling Basin Committee, 127 Campbell St, Toowoomba Qld, Australia. 4350 \\ ${ }^{d}$ School of Agriculture and Food Sciences, The University of Queensland, Brisbane Qld, Australia. 4072 \\ Email: Justine.Murray@csiro.au
}

\begin{abstract}
Engaging stakeholders and encouraging community engagement is fundamental for adoption of model results. Engagement benefits from starting from model development and continuing through to model completion and roll-out. This is especially the case when managing invasive species, where a coordinated management strategy between stakeholders works best. We use a participatory approach that combines expert knowledge and spatial data in a Bayesian network to develop risk maps of potential threats. Of particular relevance is the inclusion of management scenarios that can be manipulated to determine the effects of different strategies and combinations of coordinated strategies. Scenarios are built on expert opinion, guided from years of experience in research and management of the invasive species under field conditions. We capture their knowledge and understanding of the study system allowing us to independently validate how the model and scenarios replicate reality. Stakeholders are trained to run scenarios themselves at field days to encourage community engagement. Model results are presented as maps that visualise risk after applying different management scenarios. Maps facilitate interpretation of model results in a spatial context relevant to local communities. Capturing impacts of species invasions by running scenarios specific to targeted community groups, such as land managers, allow for increased adoption when economic incentives are introduced.

We demonstrate this with a case study using the European rabbit (Oryctolagus cuniculus), which is a serious agricultural pest in southern Queensland. We model the economic costs and effects of different rabbit management scenarios with the impacts of varying degrees of rabbit damage on different agricultural commodities. Our model allows end-users to choose the management strategies and the desired agricultural commodity, such as broccoli, spatially limited to the areas of suitable growth across the region. Model results show a distribution of costs for each modelled commodity scenario, giving end-users a range of costs unique to each agricultural region. Using ecological knowledge to understand the species' interaction within the environment and economic drivers to capture impact, our scenario modelling allows for immediate relevance to community users and ease of adoption with its participatory approach.
\end{abstract}

Keywords: $\quad$ Impact modelling, invasive species, pest management scenarios, relative costs, community engagement 
Murray et al., Using scenarios and a participatory approach to encourage model adoption in managing invasive species

\section{INTRODUCTION}

Land management is an ongoing process for agricultural and natural environments with the focus on maximum benefit for strategic costs, especially with increasingly limited available resources. Developing models can be an integral part into the understanding of the functioning of a system (Murray et al., 2014). However, management models often fall short in ease of interpretation to end-users, especially if the primary target are land managers without statistical backgrounds. There is a need to convey the information in a manner that promotes interest and a willingness to participate through a sense of community empowerment and inclusivity (Dobbs and Moore 2002).

One way to accomplish this is through engaging stakeholders through the entire model-building process. This emboldens ownership of the model from the initial concept to the end-product. However, model adoption may still be restricted to a small subset of stakeholders already keen to new ideas and implementing different strategies. This is particularly noticeable when managing invasive pests. A landholder may manage pests on their property and try different management techniques to maximise effectiveness but the neighbouring landholder may decide not to manage the pests and inadvertently provide a harbour and continual source of new pest invasions. Effective management requires a much broader and coordinated approach. Broad scale management only works with community engagement and uptake across the targeted region.

New incentives are needed to encourage increasing adoption of effective strategies to invasive species management. Quantifying economic impacts of pests may influence solutions and greater participation in broader scale management strategies. Accounting for management costs is paramount to ensure costs are less than avoided pest impact (Epanchin-Niell et al., 2015; Olson 2006). Inclusion of management scenarios allows stakeholders to determine the impact of an invasive species relative to the cost of the management strategy chosen.

In this paper, we describe a participatory approach to building a spatially-explicit economic impact model that links the ecological requirements of the invasive species and the associated economic costs of managing the species to the production loss for agricultural commodities. We demonstrate this approach using the European rabbit (Oryctolagus cuniculus) as a case study to show the economic impact of the species on different agricultural commodities in relation to the management strategy that can be chosen in different scenario settings.

\section{METHODS}

\section{Model Framework}

An innovative economic impact model was developed to combine pest habitat suitability, agricultural commodities, land use and relevant pest management strategies to determine potential agricultural production and economic loss under different management scenarios. We used a Bayesian Network (BN) to incorporate the model framework consisting of three model components: habitat suitability, management and agricultural production (Figure 1). Potential pest impact, a proxy for potential pest density, was determined by experts from suitability of the habitat, a distance threshold and the management activities that are being undertaken. The distance threshold accounted for foraging behaviour within a set distance away from suitable habitat, in this case $100 \mathrm{~m}$ for rabbits. Agricultural production loss (in percentage) was determined by experts given the potential pest impact and the commodity being produced, both of which can vary seasonally. The experts were asked to identify a production loss range with a mean and standard deviation, to capture the potential variability in loss. This was easier for the experts to agree rather than deciding on a single value. Net income after damage is the net income earned after production costs, pest management costs and income loss from pest damage are deducted from the revenue earned. The higher the agricultural loss, the more overall net income will be impacted. 
Murray et al., Using scenarios and a participatory approach to encourage model adoption in managing invasive species

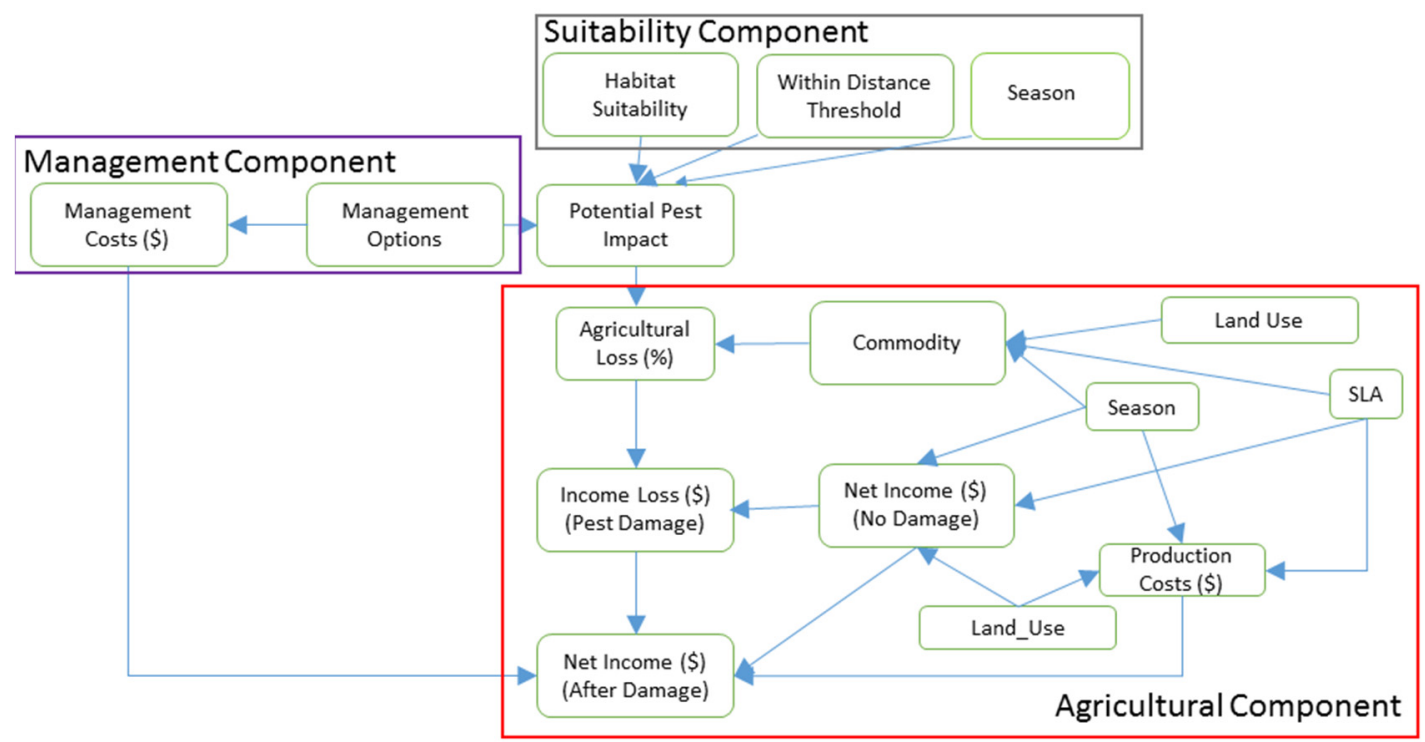

Figure 1. Schematic diagram of economic impact model showing model structure. SLA $=$ Statistical Local Area.

\section{Suitability Component}

Modelling habitat suitability involved construction of a $\mathrm{BN}$ to provide a clear graphical representation of the environmental system for pest persistence, which was subsequently used to generate spatial risk maps by linking it to relevant environmental layers within a Geographic Information System (GIS). The general methodology for habitat suitability modelling is provided in van Klinken et al., (2015) and detailed information on habitat suitability for rabbits is provided in Murray et al., (2014). We used a participatory approach to populate our models. Experts with different levels of knowledge were interviewed individually or within a group workshop setting to obtain knowledge of the rabbits' ecological requirements, management strategies and agricultural impacts. Our definition of 'experts' included researchers, land protection officers and landholders who had managed the pest for many years to ensure participation at all stakeholder levels. Involvement of landholders in model development is especially important in stimulating community interest and engagement in model outcomes.

\section{Agricultural Component}

We gathered production data for the commodities of interest from the national profit map system developed by Marinoni et al. (2012). The commodities included cereals, legumes, oilseeds, horticulture and livestock. Marinoni et al. (2012) contains a comprehensive description of the methodology used to derive their estimates. In a nutshell, the profit map system produces estimates of agricultural yields (tonnes/ha) and economic inputs/outputs (cost, revenue, profit) at a national scale and $1.1 \mathrm{~km}^{2}$ resolution, building upon agricultural statistics published by the Australian Bureau of Statistics (ABS) and the Australian Bureau of Agricultural and Resource Economics and Sciences (ABARES). Data is based on the 2005/2006 agricultural census data and is linked to the 2005/2006 Statistical Local Areas (SLAs) (Marinoni et al., 2012). We followed the method outlined in Marinoni et al. (2012) to aggregate production data for individual commodities (e.g. wheat, barley, lupins) into land use categories at $100 \mathrm{~m}$ (1 hectare) resolution. Hence, the coarse $1.1 \mathrm{~km}^{2}$ resolution grid was combined with the finer scale land use data to restrict commodity information across the grid to its relevant land use areas (e.g. data on lettuce was restricted to areas of seasonal horticulture). We also incorporated data on crop seasonality into their system to estimate inter-seasonal variation on the economic output of commodity groups.

The income loss from pest damage was calculated as: 
Murray et al., Using scenarios and a participatory approach to encourage model adoption in managing invasive species

$$
\text { Income_loss_pest_damage }=\frac{\text { Agricultural_loss }}{100} * \text { Net_income_no_damage) }
$$

The net income after damage was calculated as:

$$
\begin{aligned}
& \text { Net_income_after_damage } \\
& \qquad \begin{array}{l}
\quad \max (\text { Net_income_no_damage } \\
-(\text { Production_Costs }+ \text { Income_loss_pest_damage }+ \text { Management_costs }), 0)
\end{array}
\end{aligned}
$$

\section{Management Component}

A number of management strategies were included within the model, including "no management" (Table 1). Management strategies were identified by experts to be the most commonly used strategies currently used for this species.

Table 1. Management strategies for active management of rabbits.

\begin{tabular}{|l|l|}
\hline Management Option & Definition \\
\hline No Management & $\begin{array}{l}\text { No active management is being conducted besides what is already } \\
\text { influencing pest populations (e.g. predator pressure) }\end{array}$ \\
\hline Baiting & $\begin{array}{l}\text { Areas of active pest activity are baited with initial free feeding, then fed } \\
\text { baited food. }\end{array}$ \\
\hline Ground Shooting & $\begin{array}{l}\text { Coordinated or opportunistic shooting of individual pests from a vehicle or } \\
\text { on foot }\end{array}$ \\
\hline Trapping & $\begin{array}{l}\text { Setting traps (generally cage traps). These are generally baited to encourage } \\
\text { animals to enter. This method is very labour intensive. }\end{array}$ \\
\hline Harbour Removal & $\begin{array}{l}\text { Removal of objects that could be used as places to hide (harbour) e.g. fallen } \\
\text { trees and wood piles, rubbish piles, }\end{array}$ \\
\hline Warren Ripping & $\begin{array}{l}\text { Using heavy machinery to break up soil to around 50 cm and destroy active } \\
\text { warrens in the process }\end{array}$ \\
\hline Integrated Management & $\begin{array}{l}\text { Using a number of the above management options to manage the pest } \\
\text { species and/or coordinated management across a larger area to tackle the } \\
\text { species (e.g. across a number of individual farms or a district). }\end{array}$ \\
\hline
\end{tabular}

\section{RESULTS}

The economic impact model for rabbits allows the user to choose pest management options, individual agricultural commodities and land use to get an immediate model response as to the effect on the agricultural loss and resultant income loss. The agricultural loss altered with different management scenarios, thereby affecting the income lost from pest damage and ultimately net income (after also accounting for production costs and pest management costs) (Figure 1). To really engage the farming community on the impacts of a vertebrate pest population, scenarios were run for major individual commodities to assess the potential impact on agricultural loss and overall income loss when habitat suitability was high (Table 2). Irrigated seasonal agriculture suffered the highest losses with broccoli potentially showing a much higher loss with no management compared to integrated management. The winter crop, barley, also showed a loss but not as great as the horticultural crops. The effect on beef cattle was much less pronounced (Table 2). In the sample mapped area (Figure 2), most probable agricultural loss was limited to between 10-20\% near areas of high suitability. The area affected by rabbits was greatest with the 'no management' option. Baiting decreased the area of agricultural loss twofold and integrated management decreased the area even further (Figure 2).

\section{DISCUSSION}

Encouraging community engagement should be a major goal when developing models in pest management. Current engagement methods are limited and awareness is varied between stakeholder groups (Marzano et al., 2015). Hartter et al. (2015) suggest opinions developed from self-assessed understanding, interest in learning and a willingness to engage in extension activities tend to motivate land manager actions and lead to support for planning strategies. However, this would cover a minority of stakeholders and more investment is needed in encouraging the non-participating stakeholders within a region. In a study of the management of an invasive 
Murray et al., Using scenarios and a participatory approach to encourage model adoption in managing invasive species

weed, Johnson et al. (2011) noted farm managers preferred information by face-to-face communication with a management specialist. Our tool is designed with this in mind, addressing information gaps and offering relevant results from scenario situations.

Table 2. Management scenarios for some example agricultural commodities, given high habitat suitability showing agricultural loss, income loss due to pest damage and net income after damage. The last three columns give an overall range of values for each scenario. Values in brackets represent $80 \%$ of the range of values. Commodity information is listed in the table footnote.

\begin{tabular}{|c|c|c|c|c|c|}
\hline Commodity & $\begin{array}{l}\text { Management } \\
\text { Option }\end{array}$ & $\begin{array}{l}\text { Potential } \\
\text { pest } \\
\text { impact }\end{array}$ & $\begin{array}{l}\text { Agricultural } \\
\text { Loss (\%) }\end{array}$ & $\begin{array}{l}\text { Income Loss Pest } \\
\text { damage (\$/ha) }\end{array}$ & $\begin{array}{l}\text { Net Income after } \\
\text { damage }(\$ / \text { ha) }\end{array}$ \\
\hline Broccoli $^{1}$ & No Management & High & $\begin{array}{l}40-100 \\
(70-90)\end{array}$ & $\begin{array}{l}10,000-25,000 \\
(15,000-25,000)\end{array}$ & $\begin{array}{l}0-9,000 \\
(0-1,000)\end{array}$ \\
\hline Broccoli $^{1}$ & Baiting & Moderate & $\begin{array}{l}5-80 \\
(30-50)\end{array}$ & $\begin{array}{l}2,000-20,000 \\
(7,000-15,000)\end{array}$ & $\begin{array}{l}0-20,000 \\
(4,000-15,000)\end{array}$ \\
\hline Broccoli $^{1}$ & $\begin{array}{l}\text { Integrated } \\
\text { Management }\end{array}$ & Low & $\begin{array}{l}0-50 \\
(0-20)\end{array}$ & $\begin{array}{l}0-1,000 \\
(1,000-4,500)\end{array}$ & $\begin{array}{l}4,000-20,000 \\
(10,000-20,000)\end{array}$ \\
\hline Barley $^{2}$ & No Management & High & $\begin{array}{l}0-100 \\
(30-70)\end{array}$ & $\begin{array}{l}0-1,500 \\
(300-900)\end{array}$ & $\begin{array}{l}0-1,500 \\
(100-800)\end{array}$ \\
\hline Barley $^{2}$ & Baiting & Moderate & $\begin{array}{l}0-90 \\
(5-40)\end{array}$ & $\begin{array}{l}0-1,200 \\
(0-500)\end{array}$ & $\begin{array}{l}0-1,500 \\
(400-1,000)\end{array}$ \\
\hline Barley $^{2}$ & $\begin{array}{l}\text { Integrated } \\
\text { Management }\end{array}$ & Low & $\begin{array}{l}0-80 \\
(0-30)\end{array}$ & $\begin{array}{l}0-1,100 \\
(0-400)\end{array}$ & $\begin{array}{l}0-1,500 \\
(600-1,500)\end{array}$ \\
\hline Beef cattle $^{3}$ & No Management & High & $\begin{array}{l}0-50 \\
(0-30)\end{array}$ & $\begin{array}{l}0-100 \\
(0-100)\end{array}$ & $\begin{array}{l}0-100 \\
(0-100)\end{array}$ \\
\hline Beef cattle $^{3}$ & Baiting & Moderate & $\begin{array}{l}(0-50) \\
(0-20)\end{array}$ & $\begin{array}{l}0-100 \\
(0-100)\end{array}$ & $\begin{array}{l}0-100 \\
(0-100)\end{array}$ \\
\hline Beef cattle $^{3}$ & $\begin{array}{l}\text { Integrated } \\
\text { Management }\end{array}$ & Low & $\begin{array}{l}0-50 \\
(0-20)\end{array}$ & $\begin{array}{l}0-100 \\
(0-100)\end{array}$ & $\begin{array}{l}0-100 \\
(0-100)\end{array}$ \\
\hline
\end{tabular}

${ }^{1}$ Scenario is based on Stanthorpe SLA in Spring with the irrigated seasonal horticulture land use class.

${ }^{2}$ Scenario is based on Stanthorpe SLA in Winter with the cropping land use class.

${ }^{3}$ Scenario is based on Stanthorpe SLA in Winter with the grazing native vegetation land use class.

The economic impact model creates a valuable tool that combines agricultural production and pest management strategies with habitat suitability to determine the potential economic impact of pests in a spatially-explicit framework. It allows stakeholders to choose individual agricultural commodities and land use within the different SLAs to determine the potential agricultural loss and its related economic impact through income loss. The intended application is to help guide management and extension activities at farm to regional scales. Currently the tool runs global management scenarios but ongoing tool improvements will change it to an onthe-fly decision tool allowing farming communities to get an instant result on pest impact according to their decision on the management strategy. The model is set up to allow data to be updated easily when new information becomes available relevant to the area and pest species in question. It can be easily changed to relate to a different pest species and different commodities.

Management costs are incorporated into the model and this is accounted for in the final net income. However, the power of the tool is in its effectiveness in showing how different management options can affect the impact of the pest and potential damage to the specific commodity or the land use category. In the absence of management, rabbits in suitable habitat areas can cause considerable agricultural loss to adjacent farmland. Depending on the area and the commodity, thousands of dollars can be lost. If minimal management is done using only one method, such as baiting, the agricultural loss will be reduced. Integrated management reduces the agricultural loss substantially. 
Murray et al., Using scenarios and a participatory approach to encourage model adoption in managing invasive species
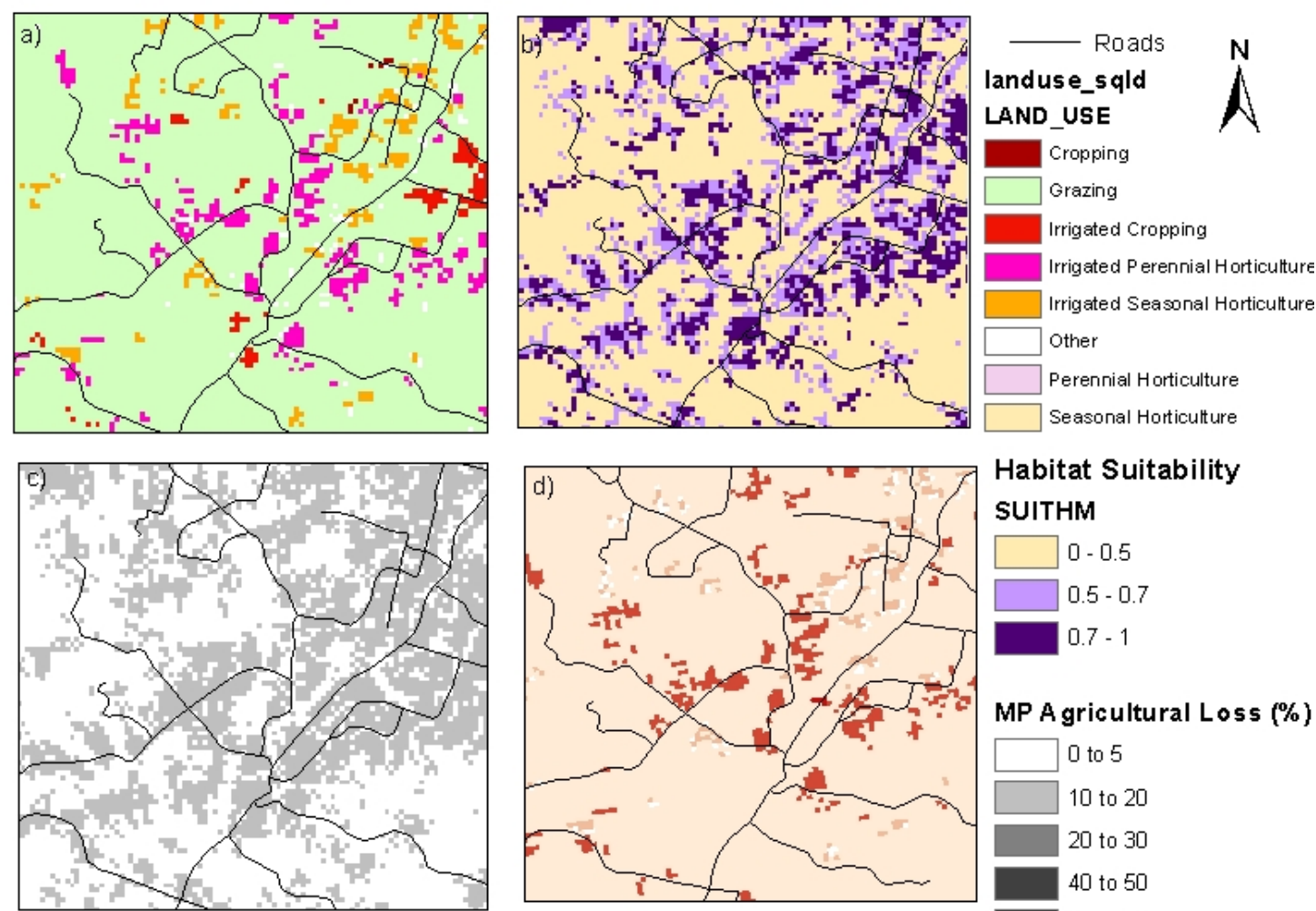

\section{Habitat Suitability} SUITHM

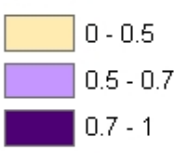

MP A gricultural Loss (\%)
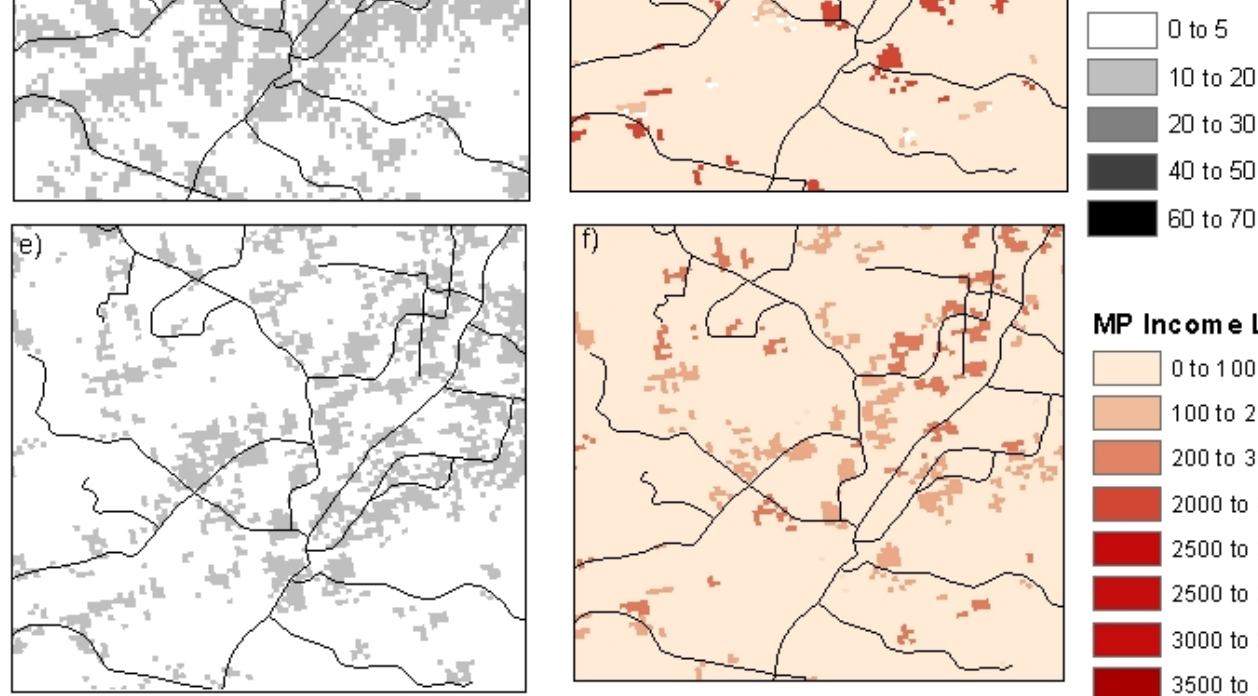

60 to 70

MP Income Loss (\$)
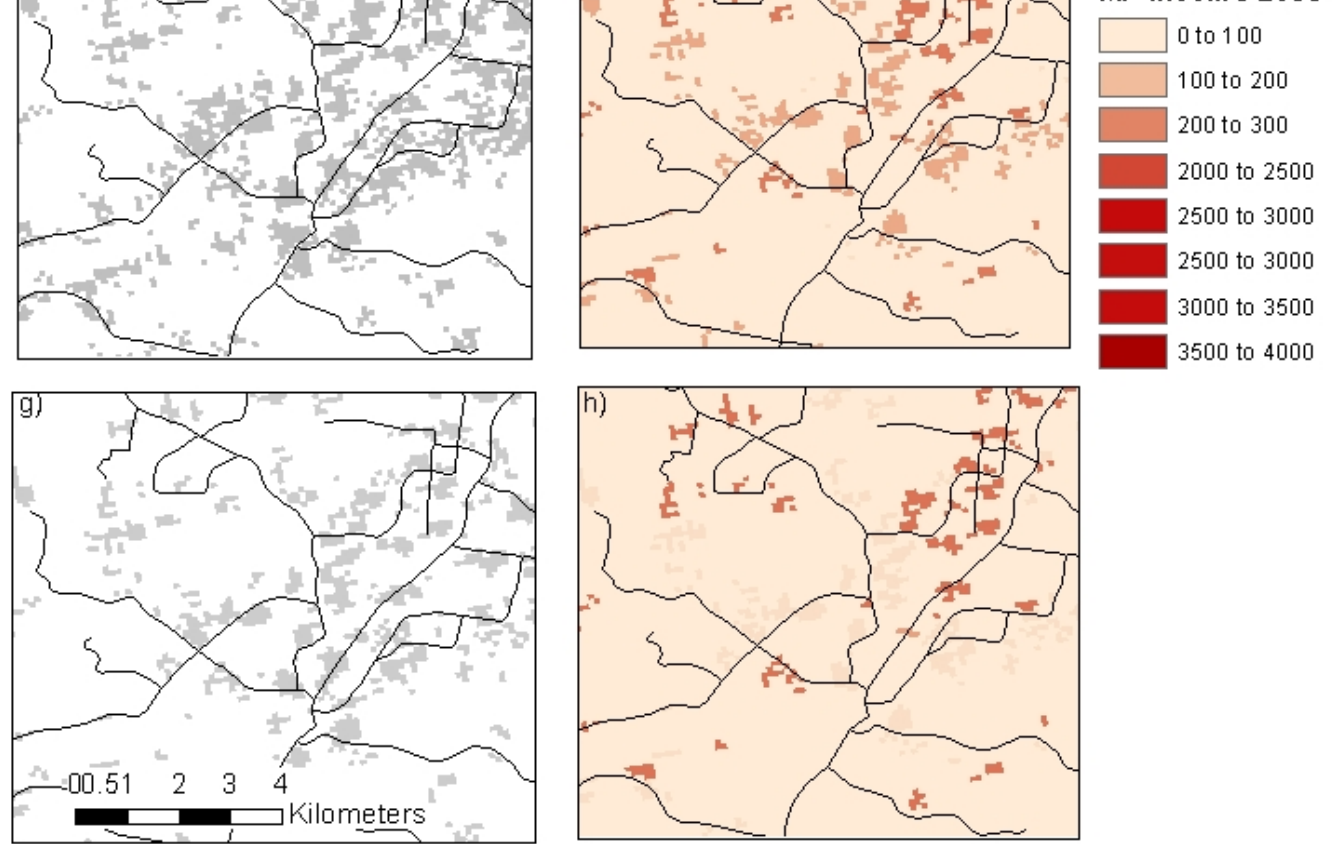

Figure 2. Mapped results showing the impact of high suitability for rabbits in summer on different land use with three management scenarios for a select area. Land use types within the area (a) and percentage most probable agricultural loss (c, e, g) are in the left column. Habitat suitability (b) and most probable income loss from pest damage $(A U D \$)(d, f, h)$ are in the right column. Scenarios shown include: no management (c, $\mathrm{d})$, baiting ( $\mathrm{e}, \mathrm{f})$, and integrated management $(\mathrm{g}, \mathrm{h}) . \mathrm{MP}=$ most probable. Note, only data-relevant classes displayed in the agricultural loss and income loss legends. 
Murray et al., Using scenarios and a participatory approach to encourage model adoption in managing invasive species

The economic impacts of rabbits has been reported at the national scale with rabbits responsible for an annual loss in economic surplus of \$206 million (Gong et al., 2009). However, this is difficult to relate at the individual paddock. Our spatially-explicit economic impact model is able to give land managers a finer scale understanding of the impact of rabbits on individual land use categories and commodities. The model has just been developed. The next phase is introducing the model to the farming community to increase engagement and adoption of integrated management strategies. The tool will be further refined with stakeholder engagement and feedback.

The tool gives land managers first-hand experience in seeing what the broad effect of different management options would have on crop yield and net income. The use of scenarios allows land managers to weigh the relative risk of the different management options on the agricultural loss, income loss and resultant net income for each commodity and thereby be more informed to make an economically sound decision towards pest management on their land. Pinpointing the proximity of pest habitat to cultivation will hopefully drive community engagement towards effective integrated management. This tool endeavours to increase community engagement with participation in broad scale pest management planning.

\section{REFERENCES}

Dobbs, L. \& Moore, C. (2002). Engaging communities in area-based regeneration: the role of participatory evaluation. Policy Studies, 23(3), 157-171.

Epanchin-Neill, R.S. \& Liebhold, A.M. (2015). Benefits of invasion prevention: effects of time lags, spread rates, and damage persistence. Ecological Economics, 116, 146-153.

Gong, W., Sinden, J., Braysher, M., Jones, R. (2009). The economic impacts of vertebrate pests in Australia. Canberra, Invasive Animals Cooperative Research Centre. 59pp. Website: http://www.pestsmart.org.au/wpcontent/uploads/2010/03/IACRC_EconomicImpactsReport.pdf Accessed 20 July 2015.

Hartter, J., Stevens, F.R., Hamilton, L.C., Congalton, R.C., Ducey, M.J., Oester, P.T.( 2015). Modelling associations between public understanding, engagement and forest conditions in the inland Northwest, USA. PLOS ONE, 10(2), e0117975.

Johnson D.D., Davies K.W., Schreder P.T. \& Chamberlain A-M. (2011). Perceptions of ranchers about medusahead (Taeniatherum caput-medusae (L.) Nevski) management on sagebrush steppe rangelands. Environmental Management, 48, 400-417.

Marzano, M., Dandy, N., Bayliss, H.R., Porth, E. \& Potter, C. (2015). Part of the solution? Stakeholder awareness, information and engagement in tree health issues. Biological Invasions. 17, 1961-1977.

Marinoni, O., Navarro Garcia, J., Marvanek, S., Prestwidge, D., Clifford, D. \& Laredo, L.A. (2012). Development of a system to produce maps of agricultural profit on a continent scale: an example for Australia. Agricultural Systems, 105, 33-45.

Murray, J.V., Berman, D.M. \& van Klinken, R.D. (2014). Predictive modelling to aid the regional-scale management of a vertebrate pest. Biological Invasions, 16(11), 2403-2425.

Olson, L.J. (2006). The economics of terrestrial invasive species: a review of the literature. Agricultural Resource Economic Review 35, 178-194.

Van Klinken, R.D., Murray, J.V. \& Smith, C. (2015). Integrative pest risk maps built from Bayesian networks. In Venette, R. (ed) Pest risk modelling and mapping for invasive alien species. CABI. pp. 171-188. 